\title{
Comparing the Outcomes and Side Effects of Administration of a Single Preoperative Dose of Vaginal Misoprostol With Intraoperative Oxytocin Infusion in Blood Loss During Abdominal Myomectomy
}

\author{
Parvin Mostafa-Gharabaghi ${ }^{1}$, Sakineh Alizadeh ${ }^{1 *}$, Simin Atashkhoye ${ }^{1}$, Manizheh Sayyah-Melli ${ }^{1}$, Mehri Jafari- \\ Shobeiri $^{1}$, Elaheh Ouladsahebmadarek ${ }^{1}$, Laya Farzadi ${ }^{1}$, Yashar Hashemi Aghdam ${ }^{2}$
}

\begin{abstract}
Objectives: This study aimed to compare the effectiveness of a single preoperative dose of misoprostol with intraoperative oxytocin infusion in abdominal myomectomies.

Materials and Methods: Patients undergoing abdominal myomectomies were divided into 2 groups. An hour before the operation, women in the misoprostol group $(n=35)$ received a single dose of vaginal misoprostol $(400 \mu \mathrm{g})$; those in the oxytocin group $(\mathrm{n}=35)$ received oxytocin (intravenous infusion of normal saline solution [30 units in $1000 \mathrm{~mL}$ ] during myomectomy).

Results: Blood loss, operation time, and need for blood transfusion were significantly reduced in the group administered with vaginal misoprostol. No difference was observed between patients in term of the period of hospitalization and complications. The results of oxytocin in abdominal myomectomy showed no significant difference.

Conclusion: Administration of a single preoperative dose of misoprostol could be a simple and reliable method for reducing intraoperative blood loss and need for postoperative blood transfusion in abdominal myomectomies.

Keywords: Misoprostol, Oxytocin, Uterine myomectomy
\end{abstract}

\section{Introduction}

Uterine fibroids are the most common female pelvic tumors occurring in about $15 \%$ to $30 \%$ of women in the reproductive age. In an epidemiologic study published in 2003 in the United States, $80 \%$ of black and nearly 70\% of white women were demonstrated to have ultrasound evidence of leiomyomas (1). When fibroids are associated with symptoms such as menorrhagia, congestive dysmenorrhoea, urinary frequency, infertility, and recurrent pregnancy losses, surgical intervention is often indicated (2). To date, there have been many fertility sparing procedures which have been used to alleviate the symptoms and enhance the fertility in women with uterine fibroids. Procedures such as uterine artery embolization (3), myolysis (4), and laparoscopic myomectomy $(5,6)$ have been used in the treatment of uterine fibroids.

A number of trials have been carried out to assess the effectiveness and safety of interventions in reducing the blood loss during myomectomy (7). Such interventions include intramyometrial vasopressin (8), intravenous oxytocin (9), tourniquets (10), chemical dissection with sodium-2-mercapto ethane sulfonate (mesna) (11), and intramyometrial bupivacaine plus epinephrine (12).

A study was conducted by Ragab and colleagues in 2014 in Saudi Arabia on 69 patients undergoing abdominal myomectomy. It was shown that the use of $400 \mu \mathrm{g}$ of vaginal or oral misoprostol 60 minutes before myomectomy reduced intraoperative bleeding and operation time (13).

Vasopressin has already been shown to decrease blood loss at the time of myomectomy $(8,10)$. Misoprostol is now being used by obstetricians and gynecologists worldwide for the evacuation of the uterus for missed abortions, intrauterine deaths, induction of labor, and the prevention of postpartum hemorrhage $(14,15)$. Its popularity especially in developing countries such as Jamaica may be accounted for the fact that it is able to produce powerful uterine contractions and lead to a reduction in myometrial hemorrhage, while being inexpensive and easy to store. Contrary to a previous study in Turkey (14), we chose to investigate the use of misoprostol in a larger subset of patients in conjunction with oxytocin in a Persian population with a high incidence of myomectomies (8).

This surgical procedure (myomectomy) involves a significant risk of hemorrhage (16). Different treatments have been proposed to reduce hemorrhage during myomectomy (17). Oxytocin administration reduces blood loss after delivery and this hormone is widely used to prevent postpartum hemorrhage (9).

In this study, we compared the effectiveness of a single preoperative dose of misoprostol with intraoperative oxy-

Received 8 March 2016, Accepted 2 October 2016, Available online 26 October 2016

${ }^{1}$ Women's Reproductive Health Research Center, Tabriz University of Medical Sciences, Tabriz, Iran. ${ }^{2}$ Azad University of Medical Sciences, Tabriz, Iran.

*Corresponding Author: Sakineh Alizadeh, Tel.: +984135547935, Email: h.moradzadeh62@yahoo.com 
tocin infusion for the reduction of blood loss at the time of myomectomy.

\section{Materials and Methods}

We enrolled 70 volunteer married women in the study. In this randomized clinical trial, a simple non-probability sampling was used. Seventy women with uterine fibroid were referred to the Alzahra hospital, Tabriz, between January 10, 2014 and February 30, 2015, who were scheduled to undergo myomectomy. They were classified into 2 groups of 35 as below: Group A, receiving $400 \mu \mathrm{g}$ of vaginal misoprostol (2 tablets of $200 \mu$ g, High Wycombe Pharmaceutical Co.) (single dose, 1 hour before surgery, and intravenous infusion of $1000 \mathrm{~mL}$ of normal saline solution at a rate of $120 \mathrm{~mL} / \mathrm{h}, 20$ minutes before the start of anesthesia until completely removing the myoma from the pelvic cavity); Group B, receiving oxytocin (3 vials of 10 units, Tamin Pharmaceutical Co.) (30 units in $1000 \mathrm{~mL}$ of normal saline solution at a rate of $120 \mathrm{~mL} / \mathrm{h}, 20$ minutes before the start of anesthesia until completely removing the myoma from the pelvic cavity).

The amount of blood accumulated in the aspiration equipment, and number of gauze pads used in the surgery for absorbing the blood were considered as the basis for calculating the patient's blood loss during the operation. To evaluate the effect of blood loss on hemoglobin and hematocrit values, the patient's hemoglobin $(\mathrm{g} / \mathrm{dL})$ and hematocrit (\%) values were measured 1 day before, and 6 and 24 hours after the operation. Abdominal incision in 2 groups was made with equal consideration. The operation was performed by the same team and hemostasis rules were observed closely. An anesthesiologist was responsible for monitoring and recording the information.

Individuals excluded from the study were: patients with cardiac, renal and pulmonary diseases, coagulopathy, and those known to be allergic to misoprostol. None of the patients had received preoperative hormonal therapy (such as a GnRH analogue or oral contraception pills) that could affect intraoperative bleeding.

\section{Randomization}

Misoprostol and oxytocin were administered randomly (using a randomized number table) by 1 nurse. The misoprostol administration was performed 60 minutes before the operation and the oxytocin administration was performed before the anesthesia until completely removing the myoma from the uterus. The operation team were not informed which of the treatments were administered the patients (misoprostol or oxytocin). The following information were recorded for patients: all of the patients' socio-demographic characteristics, as well as the size and number of preoperative myoma; uterus size in pelvic examination; operation time; preoperative and postoperative hemoglobin and hematocrit values (10); intraoperative blood loss; need for intraoperative and postoperative blood transfusion; preoperative, intraoperative and postoperative blood pressure and pulse values; complications; need for postoperative additional analgesic, and period of hospitalization.

The number and localization of myomas and the myoma diameter were established by ultrasonography. Preoperative, intraoperative, and postoperative average systolic/ diastolic blood pressures and pulse values were used to calculate changes in blood pressure $(\mathrm{mm} \mathrm{Hg}$ ) and pulse (beat/minute). Complications were defined as an increase to over $38^{\circ} \mathrm{C}$ in body heat (febrile morbidity), nausea and vomiting, diarrhea, headache, arthralgia, paresthesia, dizziness, spasm, cardiac arrest, cough, blurred vision, hearing disorders, hypotension, tachycardia, and ST depression in electrocardiogram (ECG) from the intervention time up to discharge from hospital and finally, myomectomy leading to hysterectomy.

All data were matched in terms of socio-demographic variables.

\section{Statistical Method}

Continuous and ordinal data were established as mean standard deviation (SE) and other data as nominal scale (present 1; absent 0 ). To analyze the data, SPSS version 16.0 was used. Quantitative variables as mean \pm standard deviation (SD) and qualitative data were reported as number and percentage. For comparison of quantitative variables in three groups, one-way analysis of variance (ANOVA) was used. And if the test result was significant, to compare the 2 groups, Tukey HSD test was used. Paired samples $t$ test was used to compare the groups separately before, during, and after myomectomy. $P$ value less than 0.05 was considered statistically significant.

\section{Results}

Our study indicated that compared to oxytocin, a single preoperative dose of misoprostol in myomectomies resulted in a statistically significant reduction in intraoperative blood loss and in the need for postoperative blood transfusion.

The comparison between the study and control groups did not show any significant differences for socio-demographic data, preoperative clinical data, location of myoma, and laboratory parameters $(P<0.05)$ (Tables 1 and 2$)$.

The mean hemoglobin and hematocrit in the group receiving misoprostol were $12.3 \pm 1.4 \mathrm{mg} / \mathrm{dL}$ and $37 \pm 4.4 \%$, respectively, before treatment. After treatment, 6 hours after surgery, mean hemoglobin and hematocrit were $11.5 \pm 1.4 \mathrm{mg} / \mathrm{dL}$ and $34.6 \pm 4.2 \%$, and 24 hours after surgery, they declined to $10.8 \pm 1.5 \mathrm{mg} / \mathrm{dL}$, and $32.5 \pm 4.7 \%$, respectively. In oxytocin group, the mean preoperative hemoglobin and hematocrit were $12.7 \pm 1.2 \mathrm{mg} / \mathrm{dL}$, and $38 \pm 3.9 \%$, respectively. After treatment, 6 hours after surgery, they declined to $10.1 \pm 1.1 \mathrm{mg} / \mathrm{dL}$, and $30.6 \pm 3.2 \%$, and 24 hours after surgery, to $9.8 \pm 0.7 \mathrm{mg} / \mathrm{dL}$, and $29.9 \pm 2.4 \%$, respectively $(P<0.05$, paired samples $t$ test $)$.

The average amount of bleeding in patients receiving misoprostol was $401 \pm 48 \mathrm{~mL}$ and in the group receiving oxytocin was $589 \pm 49 \mathrm{~mL}(P<0.05$, paired samples $t$ test). Duration of surgery in the group receiving misoprostol was $82 \pm 3$ minutes and in the group receiving oxytocin 
Table 1. The Sociodemographical Characteristics of Cases

\begin{tabular}{|c|c|c|c|}
\hline Characteristic & $\begin{array}{c}\text { Misoprostol } \\
\quad(n=35)\end{array}$ & $\begin{array}{l}\text { Oxytocin } \\
(n=35)\end{array}$ & $P$ Value \\
\hline Age (y) & $37.7 \pm 5.3$ & $38.4 \pm 4.6$ & $\mathrm{NS}^{\mathrm{a}}$ \\
\hline Parity (number) & $2.8 \pm 2$ & $2.8 \pm 1.5$ & $\mathrm{NS}^{\mathrm{a}}$ \\
\hline Gravida (number) & $2 \pm 1.7$ & $2 \pm 1.2$ & $\mathrm{NS}^{\mathrm{a}}$ \\
\hline Body mass index $\left(\mathrm{kg} / \mathrm{m}^{2}\right)$ & $26.4 \pm 2.9$ & $25.7 \pm 3.4$ & $\mathrm{NS}^{\mathrm{a}}$ \\
\hline Total myoma number (number) & $3.6 \pm 1.6$ & $4.3 \pm 1.6$ & $\mathrm{NS}^{\mathrm{a}}$ \\
\hline Largest myoma diameter (mm) & $91.6 \pm 35.2$ & $88.4 \pm 29.7$ & $\mathrm{NS}^{\mathrm{a}}$ \\
\hline Uterus size (pregnancy wk) & $12.1 \pm 3.5$ & $10.7 \pm 2.2$ & $\mathrm{NS}^{\mathrm{a}}$ \\
\hline \multicolumn{4}{|l|}{ Location of myomas } \\
\hline Intramural & $80 \pm 15$ & $74.3 \pm 16$ & $\mathrm{NS}^{\mathrm{a}}$ \\
\hline Subserous & $20 \pm 16$ & $22.9 \pm 17$ & $\mathrm{NS}^{\mathrm{a}}$ \\
\hline \multicolumn{4}{|l|}{ Abdominal incision } \\
\hline Phannenstiel & $50.65 \pm 5.3$ & $48.47 \pm 4.2$ & $\mathrm{NS}^{\mathrm{a}}$ \\
\hline Midline & $54.35 \pm 6.5$ & $56.53 \pm 6.1$ & $\mathrm{NS}^{\mathrm{a}}$ \\
\hline
\end{tabular}

Values are as mean \pm SD.

a $P<0.05$, statistically insignificant difference, Tukey HSD test.

Table 2. Preoperative and Postoperative Values for Patients

\begin{tabular}{|c|c|c|c|}
\hline Characteristic & $\begin{array}{l}\text { Misoprostol } \\
\quad(n=35)\end{array}$ & $\begin{array}{l}\text { Oxytocin } \\
(n=35)\end{array}$ & $P$ Value \\
\hline Preoperative $\mathrm{Hb}(\mathrm{g} / \mathrm{dL})$ & $12.3 \pm 1.4$ & $12.7 \pm 1.2$ & NS ${ }^{a}$ \\
\hline Preoperative Hct (\%) & $37 \pm 4.4$ & $38 \pm 3.9$ & $<0.05^{b}$ \\
\hline Postoperative Hb 6 hours (g/dL) & $11.5 \pm 1.4$ & $105 \pm 1$ & $<0.05^{c}$ \\
\hline Postoperative Hct 6 hours (\%) & $34.6 \pm 4.2$ & $31.6 \pm 3.2$ & $<0.05^{d}$ \\
\hline Postoperative Hb 24 hours (g/dL) & $10.8 \pm 1.5$ & $10.1 \pm 0.9$ & $<0.05^{e}$ \\
\hline Postoperative Hb 24 hours (\%) & $32.5 \pm 4.7$ & $30.5 \pm 2.9$ & $<0.05^{f}$ \\
\hline Approximate blood loss (mL) & $401 \pm 48$ & $589 \pm 49$ & $<0.05^{\mathrm{g}}$ \\
\hline Operation time (min) & $82 \pm 3$ & $93 \pm 2$ & $<0.05^{h}$ \\
\hline Need for blood transfusion & $1(3.2)$ & $3(9.7)$ & $<0.05^{i}$ \\
\hline Hospitalization period (d) & $2.1 \pm 0.4$ & $2.2 \pm 0.8$ & NS \\
\hline Complication & $4(12.5)$ & $4(12.5)$ & $\mathrm{NS}^{\mathrm{k}}$ \\
\hline
\end{tabular}

Values are as mean \pm SD

a,b $P<0.05$, statistically insignificant difference, Tukey HSD test.

$c, d, e, f, g, h, j=0.05$, statistically insignificant difference, paired sample $t$ test.

$\mathrm{l}, \mathrm{k} P<0.05$, statistically insignificant difference, chi-square test.

was recorded as $93 \pm 2$ minutes $(P<0.05$, paired samples $t$ test), and the need for blood transfusion was significantly lower in the misoprostol group. Blood transfusions were required for 1 patient in misoprostol group (1 of 35 patients, $3.2 \pm 2.2 \%$ ), and 3 patients in the oxytocin group ( 3 of 35 patients, $9.7 \pm 2.1 \%)(P<0.05$, chi-square tests). Length of stay in hospital $(P<0.05$, paired samples $t$ test) and complications during and after surgery in the two group did not show a significant difference $(P<0.05$, paired samples $t$ test).

The comparison of the changes in 2 groups showed that misoprostol was effective in reducing the bleeding during abdominal myomectomy $(P=0.005)$.

\section{Discussion}

Our study revealed that compared to oxytocin, a single preoperative dose of misoprostol in myomectomies re- sulted in a statistically significant reduction in intraoperative blood loss and in the need for postoperative blood transfusion.

Myoma is the most frequent benign pelvic mass in premenopausal and postmenopausal women. In previous studies, $25 \%$ to $50 \%$ of women reported pelvic evidence of myoma. Some of the symptoms associated with myoma include the following: abdominal pain, vaginal bleeding, pelvic pain or pressure sensation, reduced bladder capacity, constipation and infertility. Treatments include watchful waiting, medical/surgical interventions, or uterine artery embolization techniques. Therefore, in most patients with asymptomatic myoma, only care and conservative treatment are considered. In women who desire to preserve fertility, conserving surgery such as myomectomy is performed. Abdominal hysterectomy as a surgical intervention is indicated for symptomatic myoma and is 
associated with large or significant morbidity which may require blood transfusion, as excessive bleeding may occur during surgery. The main significant cause of morbidity during surgery is intraoperative bleeding that requires blood transfusion. Interventions to reduce blood loss during surgery can affect the need for blood transfusion and postoperative mortality (8).

Surgeries such as myomectomy can lead to significant blood loss during the operation, and surgical hemostasis in the patient ensures success. There are different methods for controlling bleeding and wound healing during myomectomy (17).

The volume of blood lost during abdominal myomectomy depends on the size and the location of myoma. Consecutive bleeding in the context of myoma after myomectomy is justified by the distribution of blood vessels. In numerous studies, the average amount of intraoperative bleeding during abdominal myomectomy for uterine size larger than 14 weeks have been reduced by non-mechanical techniques (10).

The major problem in abdominal myomectomy is excessive blood loss which can lead to blood transfusion, febrile morbidity, and potential loss of fertility due to hysterectomy. Identifying effective interventions to reduce bleeding in abdominal myomectomy is essential for clinical decision making based on scientific evidence. A number of safe and effective interventions to reduce bleeding during myomectomy have been proposed, including intramyometrial vasopressin, intramyometrial bupivacaine plus epinephrine, misoprostol, removal of myoma with unencrypted and close bilateral uterine and ovarian arteries (16).

Misoprostol acts through one of the 2 mechanisms to reduce blood loss. First, like prostaglandins, these prostaglandin analogs increase myometrial contractions (18). This increase in contraction is the effect of prostaglandins on vascular structures, which stem from both uterine artery and utero-ovarian anastomosis and supply blood to leiomyoma before reaching the myoma or myomas. Through this effect, vascular structures are contracted and blood flow is reduced.

The second mechanism may be the direct vasoconstrictive impact of misoprostol on uterine arteries. This effect of prostaglandin analogs was demonstrated in vitro by Baxter et al (19). Similarly, fetal anomalies have been attributed to misoprostol, reducing blood flow in uterine artery during uterine contractions (20).

The results of studies, reporting the changes in cervical resistance due to the use of misoprostol in non-pregnant patients are inconsistent (21).

The first advantage is the cost-effectiveness. Presently the most popular method for reducing hemorrhage in myomectomy is $\mathrm{GnRH}$ analogs (22). Although this is not their primary use, these $\mathrm{GnRH}$ analogs were the first treatment to be employed for myomas. However, the growth of myomas after the treatment has been noted, as well as developing the osteoporosis in long-term use; thus, $\mathrm{GnRH}$ analog use has been restricted only to decrease the myoma volume preoperatively and to reduce intraoperative blood loss $(22,23)$. Cost concerns are partially valid for vasopressin treatment as well (although not so great a concern as GnRH analogs). Some side effects have been reported as arisen from the use of intraoperative vasopressin: temporary increase in blood pressure during local vasopressin injection, bleeding at injection site, and intravascular infiltration by mistake (24). In addition, Tulandi et al (25) reported pulmonary edema after the use of local vasopressin, and Martin and Shenk (26) reported myocardial infarction. Nezhat et al (27) reported that vasopressin administered intravascularly may cause life-threatening hypotension.

The oxytocin receptor is a heptahelical membrane receptor, 389 amino acids long, which consists of 7 transmembrane helices, a short N-terminal extracellular domain, and a longer C-terminal intracellular domain (28). The effects of oxytocin on the uterus are principally meditated by the direct effects on myometrial smooth muscle cells. Oxytocin receptors are expressed in the human endometrial epithelium (29) and oxytocin stimulation of deciduous endometrium induces prostaglandin production (30). The presence of oxytocin receptor has been demonstrated in microvascular endothelial cells isolated from human myometrium (31).

Investigators have reported that the most common side effects after administration of $400 \mu \mathrm{g}$ of vaginal or oral misoprostol are chills (17.3\%), nausea and vomiting (10.2\%), headache and vertigo (7.1\%), abdominal pain (79.6\%), and diarrhea (4.1\%) (14). In addition to these side effects, some studies have reported a slight increase or decrease in blood pressure. In a striking case, a 71-yearold woman who took high doses ( $3 \mathrm{mg}$ ) of misoprostol by mistake experienced fever, tremor, tachycardia, hypertension, nausea, and abdominal cramp, but recovered with supportive treatment (32).

In our study, there were observed no important side effects in the patients who had received misoprostol. The difference between the misoprostol and oxytocin groups was not statistically significant. This is possibly because we administered a single dose of misoprostol, and after surgery the patients were either still anesthetized or under the effect of an analgesic. In the literature, all side effects of misoprostol were appeared 90 minutes after misoprostol administration in patients who were not anesthetized (33).

Other methods for reducing hemorrhage in myomectomy include mechanical vascular occlusion techniques known as tourniquet or uterine artery embolization, which have also become popular in recent years (34). All these methods require additional interventions or a separate procedure during the operation. The difficulty of access to the uterine artery with large and laterally placed myomas (such as ligamentum latum myomas) and difficulty of placing the tourniquet are significant disadvantages (35). While our method does not entail any additional intraoperative procedures. 


\section{Ethical Issues}

The protocol of this study was approved by the Local Ethics Committee for the use of humans in clinical research (ethical standards declared in Helsinki in 1983). This clinical trial has been registered in the Iranian Registry of Clinical Trials (identifier: N62014050210901IRCT).

\section{Conflict of Interests}

The authors declare no conflict of interests.

\section{Financial Support}

Financial support was provided by Women's Reproductive Health Research Center, Tabriz University of Medical Sciences.

\section{Acknowledgments}

We would like to thank the authorities of Women's Reproductive Health Research Center, Tabriz University of Medical Sciences, for the scientific and financial support of this research. This study was done as a thesis for specialist degree of Sakineh Alizadeh in Women's Reproductive Health Research Center, Tabriz University of Medical Sciences.

\section{References}

1. Zaloudek C, Norris H. Mesenchymal Tumors of the Uterus. In: Kurman R, ed. Blausteins Pathology of the Female Genital Tract. New York: Springer-Velarg; 1987:408-737.

2. Buttram VC Jr, Reiter RC. Uterine leiomyomata: etiology, symptomatology, and management. Fertil Steril. 1981;36(4):433-45.

3. Goodwin SC, Spies JB, Worthington-Kirsch R, et al. Uterine artery embolization for treatment of leiomyomata: long-term outcomes from the FIBROID Registry. Obstet Gynecol. 2008;111(1):22-33. doi:10.1097/01. AOG.0000296526.71749.c9.

4. Kim CH, Kim SR, Lee HA, Kim SH, Chae HD, Kang BM. Transvaginal ultrasound-guided radiofrequency myolysis for uterine myomas. Hum Reprod. 2011;26(3):559-63. doi: 10.1093/humrep/deq366.

5. Dubuisson JB, Fauconnier A, Deffarges JV, Norgaard C, Kreiker G, Chapron C. Pregnancy outcome and deliveries following laparoscopic myomectomy. Hum Reprod. 2000;15(4):869-73.

6. Kongnyuy EJ, van den Broek N, Wiysonge CS. A systematic review of randomized controlled trials to reduce hemorrhage during myomectomy for uterine fibroids. Int J Gynaecol Obstet. 2008;100(1):4-9. doi: 10.1016/j. ijgo.2007.05.050.

7. Neilson JP. Interventions to reduce haemorrhage during myomectomy for fibroids. Obstet Gynecol. 2007;109(5):11978. doi: 10.1097/01.aog.0000263778.58572.25.

8. Frederick J, Fletcher H, Simeon D, Mullings A, Hardie M. Intramyometrial vasopressin as a haemostatic agent during myomectomy. Br J Obstet Gynaecol. 1994;101(5):435-7.

9. Atashkhoei S, Fakhari S, Pourfathi H, Bilehjani E, Garabaghi PM, Asiaei A. Effect of oxytocin infusion on reducing the blood loss during abdominal myomectomy: a double-blind randomised controlled trial. BJOG. 2017;124:292-8. doi: 10.1111/1471-0528.14416.

10. Fletcher H, Frederick J, Hardie M, Simeon D. A randomized comparison of vasopressin and tourniquet as hemostatic agents during myomectomy. Obstet Gynecol. 1996;87(6):1014-8.

11. Benassi L, Lopopolo G, Pazzoni F, et al. Chemically assisted dissection of tissues: an interesting support in abdominal myomectomy. J Am Coll Surg. 2000;191(1):65-9.

12. Zullo F, Palomba S, Corea D, et al. Bupivacaine plus epinephrine for laparoscopic myomectomy: a randomized placebo-controlled trial. Obstet Gynecol. 2004;104(2):2439. doi: 10.1097/01.AOG.0000132801.41880.e8.

13. Ragab A, Khaiary M, Badawy A. The use of single versus double dose of intra-vaginal prostaglandin E2 "Misoprostol" prior to abdominal myomectomy: A randomized controlled clinical trial. J Reprod Infertil. 2014;15(3):152-6.

14. Celik H, Sapmaz E, Serhatlioglu S, Parmaksiz C, Altingul A. Effect of intravaginal misoprostol use on uterine artery blood flow in patients with myoma uteri. Fertil Steril. 2003;80(6):1526-8.

15. Elsheikh A, Antsaklis A, Mesogitis S, et al. Use of misoprostol for the termination of second trimester pregnancies. Arch Gynecol Obstet. 2001;265(4):204-6.

16. LaMorte AI, Lalwani S, Diamond MP. Morbidity associated with abdominal myomectomy. Obstet Gynecol. 1993;82:897-900.

17. Lethaby A, Vollenhoven B, Sowter M. Efficacy of pre-operative gonadotrophin hormone releasing analogues for women with uterine fibroids undergoing hysterectomy or myomectomy: a systematic review. BJOG. 2002;109(10):1097-108.

18. Wray S. Uterine contraction and physiological mechanisms of modulation. Am J Physiol. 1993;264(1 Pt 1):C1-18.

19. Baxter GS, Clayton JK, Coleman RA, Marshall K, Sangha $\mathrm{R}$, Senior J. Characterization of the prostanoid receptors mediating constriction and relaxation of human isolated uterine artery. Br J Pharmacol. 1995;116(1):1692-6.

20. Gonzalez CH, Marques-Dias MJ, Kim CA, et al. Congenital abnormalities in Brazilian children associated with misoprostol misuse in first trimester of pregnancy. Lancet 1998;351(9116):1624-7. doi: 10.1016/s01406736(97)12363-7.

21. Perrone JF, Caldito G, Mailhes JB, Tucker AN, Ford WR, London SN. Oral misoprostol before office endometrial biopsy. Obstet Gynecol. 2002;99(3):439-44.

22. Friedman AJ, Rein MS, Harrison-Atlas D, Garfield JM, Doubilet PM. A randomized, placebo-controlled, doubleblind study evaluating leuprolide acetate depot treatment before myomectomy. Fertil Steril. 1989;52(2):728-33.

23. Stewart EA. Uterine fibroids. Lancet. 2001;357(9252):2938. doi: 10.1016/s0140-6736(00)03622-9.

24. Okin CR, Guido RS, Meyn LA, Ramanathan S. Vasopressin during abdominal hysterectomy: a randomized controlled trial. Obstet Gynecol. 2001;97(6):867-72.

25. Tulandi T, Beique F, Kimia M. Pulmonary edema: a complication of local injection of vasopressin at laparoscopy. Fertil Steril. 1996;66(3):478-80.

26. Martin JD, Shenk LG. Intraoperative myocardial infarction after paracervical vasopressin infiltration. Anesth Analg. 1994;79(6):1201-2.

27. Nezhat F, Admon D, Nezhat CH, Dicorpo JE, Nezhat C. Life-threatening hypotension after vasopressin injection during operative laparoscopy, followed by uneventful repeat laparoscopy. J Am Assoc Gynecol Laparosc. 1994;2(1):83-6.

28. Gimpl G, Fahrenholz F. The oxytocin receptor system: 
structure, function, and regulation. Physiol Rev. 2001;81:629-83.

29. Dawood MY, Lau M, Khan-Dawood FS. Localization and expression of oxytocin receptor and its messenger ribonucleic acid in peri-implantation phase human endometrium during control and clomiphene-treated cycles. Am J Obstet Gynecol. 1999;181(1):50-6.

30. Fuchs AR, Husslein P, Fuchs F. Oxytocin and the initiation of human parturition. II. Stimulation of prostaglandin production in human decidua by oxytocin. Am J Obstet Gynecol. 1981;141(6):694-7.

31. Weston GC, Cann L, Rogers PA. Myometrial microvascular endothelial cells express oxytocin receptor. BJOG. 2003;110(2):149-56.
32. Graber DJ, Meier KH. Acute misoprostol toxicity. Ann Emerg Med. 1991;20(5):549-51.

33. Zieman M, Fong SK, Benowitz NL, Banskter D, Darney PD. Absorption kinetics of misoprostol with oral or vaginal administration. Obstet Gynecol. 1997;90(1):88-92. doi: 10.1016/s0029-7844(97)00111-7.

34. Ginsburg ES, Benson CB, Garfield JM, Gleason RE, Friedman AJ. The effect of operative technique and uterine size on blood loss during myomectomy: a prospective randomized study. Fertil Steril. 1993;60(6):956-62.

35. Amato P, Roberts AC. Transient ovarian failure: a complication of uterine artery embolization. Fertil Steril. 2001;75(2):438-9.

Copyright ( 2017 The Author (s); This is an open-access article distributed under the terms of the Creative Commons Attribution License (http://creativecommons.org/licenses/by/4.0), which permits unrestricted use, distribution, and reproduction in any medium, provided the original work is properly cited. 